\title{
Cell adhesion and growth on synthetic hydrogel beads
}

\author{
K SHIVAKUMAR, R RENUKA NAIR, A JAYAKRISHNAN, \\ C C KARTHA and M S VALIATHAN \\ Sree Chitra Tirunal Institute for Medical Sciences and Technology, Trivandrum 695011 , \\ India.
}

\begin{abstract}
Hydrolysed poly(methyl methacrylate) microspheres with carboxyl residues distributed throughout the matrix were tested for their ability to support cell adhesion and growth. Cell growth as determined by protein content, phase contrast and scanning electron microscopy showed that these microspheres are growth-supportive. Further, preliminary experiments pointed to their usefulness in microcarrier culture.
\end{abstract}

Keywords. Cell adhesion; cell growth; synthetic hydrogel beads; hydrolysed poly(methyl methacrylate) microspheres; microcarrier culture.

\section{Introduction}

Over the last one hundred years, the technique of tissue culture has gone through several improvisations, providing invaluable insights into the morphology, biochemistry and physiology of specific types of living cells in a defined environment. An important application of the tissue culture technique is the production of many compounds of biological importance such as enzymes, vaccines, hormones, monoclonal antibodies and antibiotics. Many of these compounds can be obtained by recombinant DNA technology. Alternatively, they can be produced more economically from non-transformed mammalian cells in culture. Large-scale production of such compounds would, however, require large numbers of the cells producing them. Microcarrier culture, first conceived by van Wezel way back in 1967, introduces new possibilities for the large-scale culture of anchorage-dependent animal cells (van Wezel 1967).

Microcarriers are small spheres so designed as to support cell adhesion and growth. They provide a charged culture surface, a high surface area to volume ratio, a beaded form, good optical properties and a suitable density. Since the advent of microcarrier technology, a number of materials have been used successfully as microcarriers. These include DEAE-dextran (Levine et al 1977), porous silica (Hirtenstein et al 1980), polystyrene plastic (Johansson and Nielsen 1980), and polyacrylamide (Hirtenstein et al 1980).

Smooth, spherical, hydrophilic beads have been derived from cross-linked poly (methylmethacrylate) beads by alkaline hydrolysis in ethylene glycol (Jayakrishnan et al 1989). Hydrogels are known to be biocompatible and permeable but there are only a very few reports on the interaction between a cell and a hydrogel surface (Folkman and Maseona 1978; Rosen and Schway 1979). This presentation will describe the work that has led to the successful culture of human skin fibroblasts and human heart and lung cells on the hydrogel beads. The potential of the microspheres for use in microcarrier culture will be discussed. A brief description of the phenomenon of cell adhesion to biomaterials and the applications of microcarrier culture will also be attempted. 


\section{Cell adhesion is a multi-step process}

The adhesion of cells to culture surfaces is fundamental to both the traditional monolayer culture and the microcarrier culture. Cell attachment to a surface is brought about by certain 'attachment factors' which include the matrix-associated glycoproteins such as fibronectin, laminin, collagens and proteoglycans and the subsurface microfilament-associated proteins such as vinculin, $\alpha$-actinin and the src protein. These factors are concentrated at the sites of cell-substratum interaction. They have multiple binding sites with affinity for both cell surface and culture surface with the result that they are able to foster cell adhesion.

Cell adhesion is a multi-step process involving (i) adsorption of the attachment factors on the culture surface, (ii) contact between the cell and the culture surface, (iii) attachment of the cells to the surface, and (iv) spreading of the attached cells. The attachment factors are provided by the serum and, in many cases, the cells themselves synthesise and secrete these molecules. The interaction between a cell and the attachment factors can be studied in a number of ways. Some of the useful approaches have been. (a) cell attachment and spreading on plastic substrates, followed by analysis of the factors left behind by the cells upon detachment, (b) affinity chromatography of extracellular molecules, and (c) the use of anti-cell surface antibodies that inhibit cell adhesion.

\section{Cell growth on microcarrier}

Basic principles which apply to conventional cell culture apply to microcarrier culture as well. The applications of microcarriers fall into mainly three categories, (i) high yield production of viruses, cells and cell products, (ii) studies on cells in vitro, and (iii) routine cell culture techniques.

Microcarrier culture provides for large-scale culture of viruses and animal cells and has been particularly useful in the production of different types of vaccines. Vaccines produced by the microcarrier system include those against rabies, polio, influenza and foot-and-mouth disease (van Hemert et al 1969; Meignier et al 1980; van Wezel et al 1980; Montagnon et al 1981). The technique has also enabled the growth of large number of human colon carcinoma cells for the production of carcinoembryonic antigen (Page and Dufour 1979) and the production of plasminogen activator from transformed mouse fibroblasts.

High density cell cultures have also provided great insights into cell function, metabolism and differentiation because microcarriers ensure normal cell function and differentiation in vitro. Highly specialised endocrine cells like the pancreatic cells have been maintained in microcarrier culture and these cells have been found to sustain the synthesis and release of insulin during a 7-day growth period. Another important application of the technique is in the isolation of plasma membranes of a high degree of purity. When cells grown on microcarriers are subjected to hypotonic lysis followed by brief sonication, plasma membranes with less than $1 \%$ contamination from internal membranes remain attached to the microcarrier surface (Gottlib and Searls 1980).

Microcarriers offer important advantages in routine cell culture as well. Cells grown on them can be easily transferred from one culture vessel to another without the use of proteases or chelators which affect the integrity of the plasma membrane 
(Ryan et al 1980). Further, it is possible to maintain prolonged periods of exponential growth of cells by diluting confluent microcarrier cultures with freshly added microcarriers (Crespi and Thilly 1981).

\section{Materials and methods}

Cell culture: The general steps involved in setting up a culture are outlined below. Human fetuses were obtained following medical termination of pregnancy in the early weeks of gestation ( $8-10$ weeks). The skin, lungs and heart were dissected out and washed repeatedly in Hank's balanced salt solution (HBSS) containing the antibiotics, penicillin $(1 \mathrm{mg} / \mathrm{ml})$ and streptomycin $(0.5 \mathrm{mg} / \mathrm{ml})$. The tissue was then sliced in HBSS and subjected to enzymatic dissociation. For the isolation of fibroblasts and lung cells, the disaggregation medium containing $0.05 \%$ trypsin, in $\mathrm{Ca}-\mathrm{Mg}$ free HBSS, and for the isolation of heart cells, a disaggregation medium containing $0.03 \%$ trypsin, $0.03 \%$ collagenase, $0.005 \%$ DNase, $1 \% \mathrm{BSA}, \mathrm{MgSO}_{4}$, $\mathrm{MgCl}_{2}$ and $\mathrm{CaCl}_{2}$ were used. Dissociation was carried out at $37^{\circ} \mathrm{C}$ for $20 \mathrm{~min}$ on a magnetic stirrer at low speed. The supernatant was collected and the trypsin inactivated with an equal volume of $20 \%$ fetal calf serum. The disaggregation was repeated with the residue and the supernatants were pooled. For heart cells, the first supernatant was discarded as it would contain cell debris, fibroblasts and red blood cells. The pelletted cells were resuspended at a cell density of $1 \times 10^{6}$ cells $/ \mathrm{ml}$ in Medium 199 (Gibco Laboratories) containing 20\% fetal bovine serum, penicillin $(1 \mathrm{mg} / \mathrm{ml})$ and gentamycin $(0.05 \mathrm{mg} / \mathrm{ml})$. Cultures were maintained at $37^{\circ} \mathrm{C}$ in a humidified atmosphere with $5 \% \mathrm{CO}_{2}$. The medium was changed every third day, using Dulbecco's modified Eagles' medium with $10 \%$ fetal bovine serum and antibiotics for the change. The cells attached and grew to form confluent layers. The cell types could be easily identified by microscopic examination.

\subsection{Preparation of hydrogel beads for culture}

Beads with carboxyl functions and EWC of $94 \%$ were used in all experiments. They were allowed to swell in $0.2 \mathrm{M}$ phosphate-buffered saline and autoclaved at $103.42 \mathrm{kPa}$ for $10 \mathrm{~min}$. The beads were pre-swollen in Medium 199 with $20 \%$ fetal bovine serum $24 \mathrm{~h}$ before the culture.

The cells were seeded on the hydrogel surface at a density of $1 \times 10^{6}$ cells $/ \mathrm{ml}$ and maintained as described above. Commercial tissue culture plates were seeded in an identical manner for comparison.

\subsection{Cell growth}

Growth was monitored on the 6th day of culture in terms of cellular protein content by Lowry's method (Lowry et al 1951). Protein adsorbed by the bead was subtracted. The adhesion of cells on the hydrogel was visualised by phase contrast (Nikon) and scanning electron microscopy (Cambridge).

\subsection{Scanning electron microscopy}

The cells on the beads were fixed with $2 \%$ phosphate-buffered glutaraldehyde for 
$2 \mathrm{hrs}$ and post-fixed with $1 \% \mathrm{OsO}_{4}$ for $1 \mathrm{~h}$. After rinsing in phosphate buffer, dehydration was carried out using a graded series of alcohol. The beads with the cells were vacuum dried after transferring from $100 \%$ ethanol through liquid $\mathrm{N}_{2}$. They were mounted on stubs, smeared with sticky conducting paint, coated with silver in a vacuum coating unit and examined by scanning electron microscopy.

\section{Results}

Phase contrast microscopy (figure 1) and scanning electron microscopy (figures 2 and 3) of fibroblasts and lung (predominantly epithelial) and heart (predominantly myocardial) cells clearly show that these different cell types adhere well to the hydrogel surface. Figure 2 is a scanning electron micrograph showing single-cell attachment to the substratum. Filopodia extending from the cell to the substratum can be clearly seen. Figure 3 shows the cells forming 'bridges' between the beads.

The growth of cells on the beads was quantified in terms of cellular protein content. It is clear from table 1 that the hydrogel surface supports the growth of three types of cells. The values for growth on the hydrogel compared well with those for growth on the commercial tissue culture plate.

The usefulness of hydrogel microspheres is brought out by a simple calculation. The surface area available for the growth of, say, fibroblasts on the tissue culture plate was $21 \mathrm{~cm}^{2}$ which gave a total yield of $290 \mu \mathrm{g}$ protein. With the hydrogel beads, a total bead surface area of $12.2 \mathrm{~cm}^{2}$ was obtained even as the beads covered only $11.9 \%$ (i.e. $2.5 \mathrm{~cm}^{2}$ ) of the surface area of the dish for a yield of $256 \mu \mathrm{gm}$ protein. Theoretically, if the entire surface area of the dish is covered with beads, a total (bead) surface area of $102.5 \mathrm{~cm}^{2}$ would yield $2151 \mu \mathrm{gm}$ proteins. Similar calculation can be made for the lung and heart cells too. In fact, fibroblasts were seeded on the beads completely covering the dish. Yields about three times higher than from the plain dish were obtained. It should be mentioned at this point that where large scale cultivation of cells using microcarriers is desired, suspension cultures rather than static cultures (as employed in this study) would ensure better results.

\section{Conclusion}

These results indicate that the hydrogel is growth-supportive even without

Table 1. Cell growth on hydrogel surface.

\begin{tabular}{lcc}
\hline & \multicolumn{2}{c}{$\begin{array}{c}\text { Cell yield } \\
\left(\mu \mathrm{gm} / \mathrm{cm}^{2}\right)\end{array}$} \\
\cline { 2 - 3 } Cell type & Plastic & Hydrogel \\
\hline Fibroblasts & 13.8 & 20.9 \\
Lung cells & 33.7 & 25.5 \\
Heart cells & 10.1 & 25.15 \\
\hline
\end{tabular}




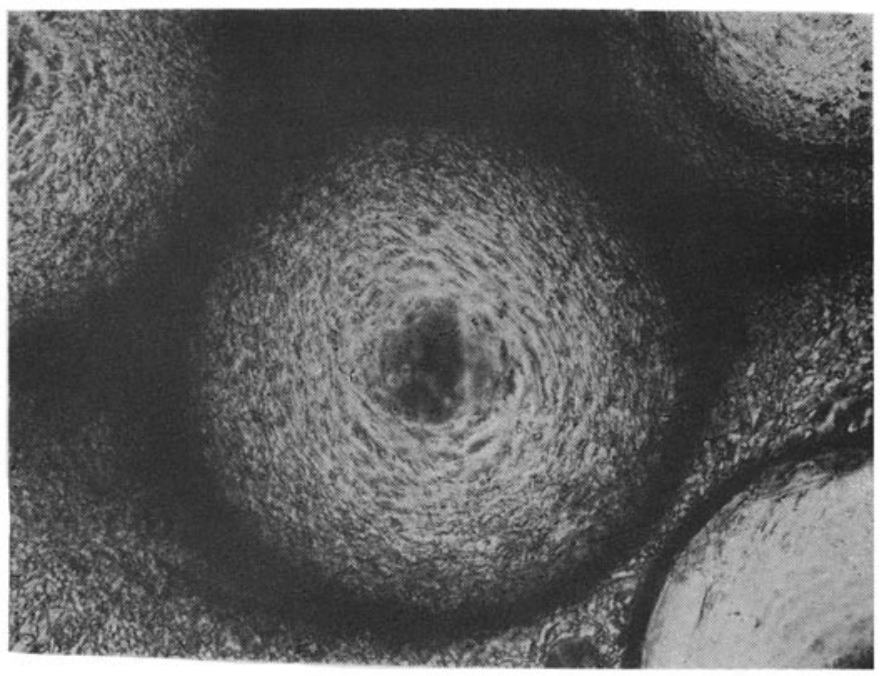

Figure 1. Phase contrast micrograph of cells attached to the hydrogel beads $(\times 50)$.

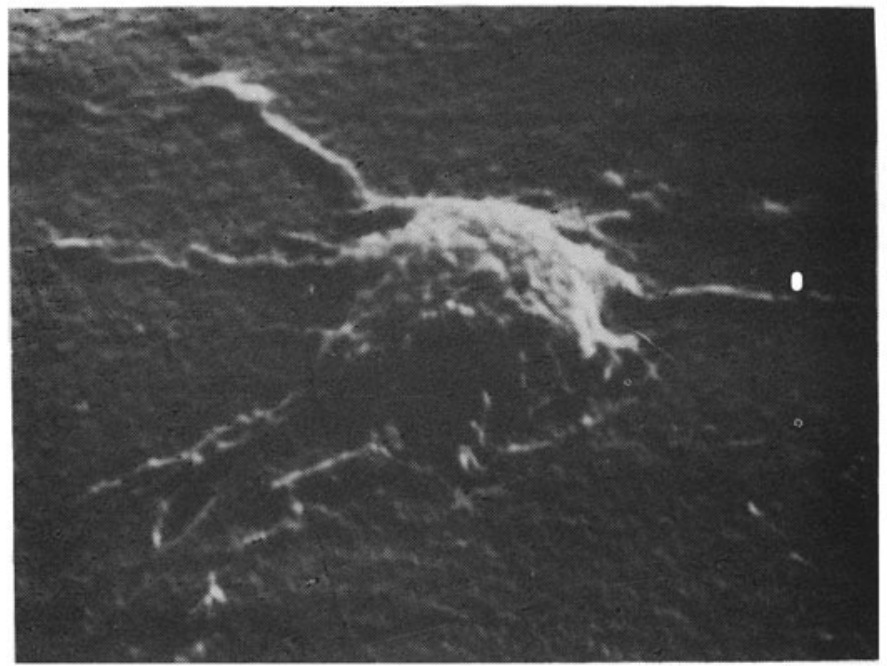

Figure 2. Scanning electron micrograph of single cell attachment to the hydrogel beads $(\times 2500)$.

derivatization with biomolecules that normally promote cell adhesion and growth. It is reasonable to presume that derivatization and the employment of suspension cultures would further improve the performance of the material. 


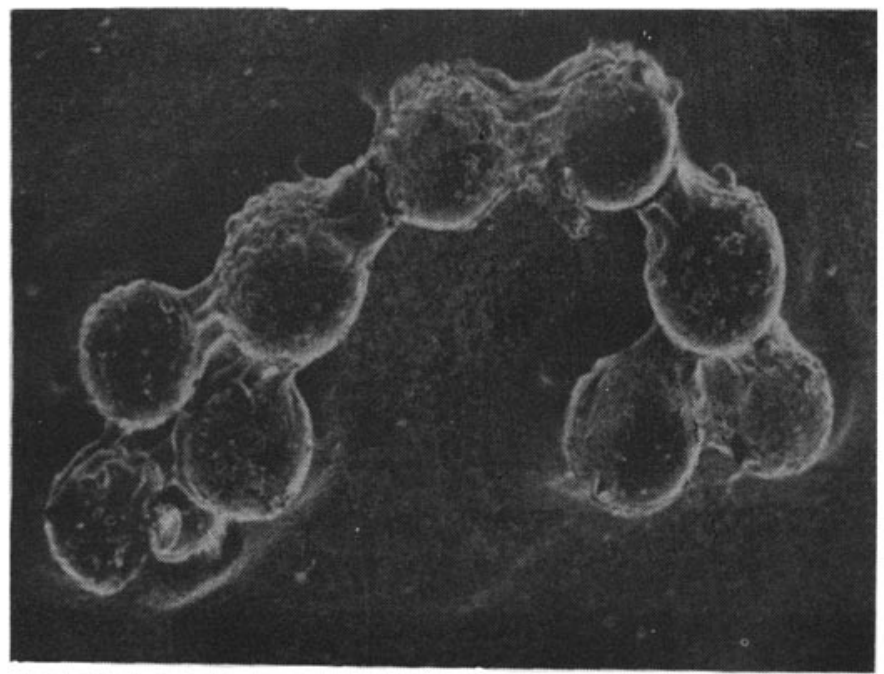

Figure 3. Scanning electron micrograph of cells forming bridges between the hydrogel beads $(\times 25)$.

\section{References}

Crespi C L and Thilly W G 1981 Biotechnol. Bioeng. 23983

Folkman J and Moseona A 1978 Nature (London) 273345

Gottlib L J and Searls D B 1980 Biochim. Biophys. Acta 602207

Hirtenstein M, Clark J, Lindgren G and Vretblad D 1980 Dev. Biol. Standard 46109

Jayakrishnan A, Chitambara Thanoo B, Rathinam K, Mandalam K R, Rao V R K, Lal A V and Mohanthy M 1989 Bull. Mater. Sci. 1217

Johansson A and Nielsen V 1980 Dev. Biol. Stand. 46125

Levine D L, Wong J S, Wang D I C and Thilly W C 1977 Somatic Cell Genet. 3144

Lowry O H, Rosebrough N J, Farr A L and Randall R J $1951 \mathrm{~J}$. Biol. Chem. 193265

Meignier B, Mongeot H and Farre H 1980 Dev. Biol. Stand. 46249

Montagnon B J, Fanget B and Nicolas A J 1981 Dev. Biol. Stand. 4755

Page $M$ and Dufour C 1979 J. Cell. Biol. 83 A302

Rosen J J and Schway M B 1979 ACS Organic Coating and Plastics Chemistry 40636

Ryan U S, Mortaro M and Whitaker C 1980. Tissue Cell 12619

van Hemert P, Kilburn D G and van Wezel A L 1969 Biotechnol. Bioeng. 11875

Van Wezel A L 1967 Nature (London) 21664

Van Wezel A L, van der Velden, de Groot C A M and van Herwaarden J A N 1980 Dev. Biol. Stand. 46 151 